\title{
CONTROLE GENÉTICO DA RESISTÊNCIA AO MOSAICO COMUM EM LINHAGENS DE MILHO TROPICAL
}

\author{
ADILSON RICKEN SCHUELTER ${ }^{1}$, ISABEL REGINA PRAZERES DE SOUZA², ELIZABETH DE \\ OLIVEIRA $^{2}$, CLAUDIA TEIXEIRA GUIMARÃES ${ }^{2}$ \\ ${ }^{1}$ Universidade Paranaense. Av. Parigot de Souza 3636, CEP 85903-170 Toledo, PR. E-mail: adilson@ unipar.br (autor \\ para correspondência) \\ ${ }^{2}$ Pesquisadoras, Embrapa Milho e Sorgo. Caixa Postal 151, CEP 35701-970 Sete Lagoas, MG.
}

Revista Brasileira de Milho e Sorgo, v.2, n.3, p.103-110, 2003

RESUMO - A contínua diversificação das épocas de cultivo do milho, na maioria das regiões produtoras, tem contribuído para o aumento na incidência e na severidade de doenças, incluindo a virose mosaico comum causada por potyvirus. Tem sido verificado que, de forma predominante, uma estirpe do maize dwarf mosaic virus (MDMV) é o agente causal dessa virose no Brasil. O uso de cultivares resistentes é o método mais eficiente e econômico para o controle dessa virose. Entretanto, a identificação de fontes de resistência e o estudo da sua herança são requerimentos primordiais para o sucesso de programas de melhoramento visando a produção de cultivares resistentes. Assim, o presente trabalho teve como objetivo o estudo do controle genético da resistência ao mosaico comum do milho usando-se duas linhagens resistentes (L18 e L520) e uma susceptível (L19). Os genitores e as gerações $\mathrm{F}_{1}, \mathrm{~F}_{2}$, $\mathrm{RC}_{1.1}$ e RC ${ }_{1.2}$ foram submetidos à inoculação artificial, quando as plântulas apresentavam-se no estádio de cinco folhas e a fenotipagem, realizada aos 15 e aos 30 dias após a inoculação. Os resultados das análises genético-estatísticas pelo teste de $c^{2}$ mostraram que a resistência ao vírus do mosaico comum é condicionada por um gene com dominância completa em ambas as linhagens resistentes. O teste de alelismo entre L18 e L520 detectou a proporção fenotípica de $15(\mathrm{R})$ : $1(\mathrm{~S})$ na geração $\mathrm{F}_{2}$, indicando que as linhagens resistentes portam genes distintos.

Palavras-chave: Zea mays, maize dwarf mosaic virus (MDMV), potyvirus, resistência genética.

\section{GENETIC CONTROL OF MAIZE DWARF MOSAIC VIRUS IN TROPICAL MAIZE INBRED LINES}

\begin{abstract}
The continuous cropping in the major corn growing areas has contributed to the increase in the incidence and severity of diseases, including the diseases caused by potyvirus. It has been predominantly observed that one strain of the maize dwarf mosaic virus (MDMV) is the causal agent of the potyvirus - induced - mosaic in Brazil. The use of resistant cultivars is the most efficient method to protect crops against this virus disease. However, the identification of resistance sources and its genetic control are important requirements to establish successful breeding programs aiming the production of resistant cultivars. Thus, the objective of this study was to determine the genetic basis of resistance to maize dwarf mosaic virus using two resistant (L18 and L520) and one susceptible (L19) maize inbred lines. The parents and their respective generations $\mathrm{F}_{1}, \mathrm{~F}_{2}, \mathrm{BC}_{1.1}$ and $\mathrm{BC}_{1.2}$ were artificially inoculated and the symptoms evaluation was done at 15 and 30 days after inoculation. The genetic-statistic results analyzed by the chisquare test showed that the resistance to maize dwarf mosaic virus is conditioned by a single
\end{abstract}


gene with complete dominance in both resistant inbred lines. Besides, the allelism test between L18 and L520 detected a phenotypic proportion of $15(\mathrm{R}): 1(\mathrm{~S})$ in the $\mathrm{F}_{2}$ generation, suggesting that the resistant inbred lines carry different genes.

Key-words: Zea mays, maize dwarf mosaic virus (MDMV), potyvirus, genetic resistance.

O cultivo contínuo de milho, como acontece em grande parte das regiões produtoras do país, é um dos fatores que contribuem para o surgimento de novos problemas aos produtores, o que requer esforços da pesquisa para que o nível de produtividade possa ser mantido. Nesse contexto, tem-se verificado o aumento na incidência e na severidade das doenças que acometem o milho, incluindo a virose mosaico comum (Almeida et al., 2001).

O mosaico comum do milho apresenta ampla distribuição em nível mundial, sendo que nos EUA e na Austrália foi demonstrado que pode ser causado por quatro espécies diferentes de potyvirus: Maize dwarf mosaic virus (MDMV), Sugarcane mosaic virus (SCMV), Johnsongrass mosaic virus (JGMV) e Sorghum mosaic virus (SrMV) (Shukla et al., 1994). Recentemente, foi demonstrado, no Brasil, que um cDNA de 335 pb, obtido de RNA a partir do vírus purificado de folhas de milho com sintomas de mosaico, apresentou similaridade das sequiências de nucleotídeos entre esses quatro potyvirus, nas seguintes proporções MDMVB (86,3\%), SCMV (81,8\%), SrMV (77,1 \%) e JGMV (70,2 \%) (Almeida et al., 2000). Avaliações posteriores empregando sondas de DNA mostraram predominância do MDMV em amostras de folhas de milho com sintomas de mosaico provenientes da área experimental da Embrapa em Sete Lagoas, MG, ede diferentes regiões produtoras (Mello, 2000).

A incidência e a severidade do mosaico comum do milho começou a ser expressiva a partir dos anos 90, sendo atualmente encontrada em praticamente todas as regiões produtoras de milho do Brasil,apresentando maior severidade principalmente na época das chuvas, podendo reduzir a produção de grãos de variedades susceptíveis em até $60 \%$ (Waquil et al., 1996; Fernandes \& Oliveira, 1997). O método mais eficiente para o controle dessa doença é a utilização de cultivares resistentes, que atualmente inexistem no mercado brasileiro. Essa virose tem sido estudada por pesquisadores norte-americanos desde a década de 60 (Williams \& Alexander, 1965), quando foram iniciados programas de melhoramento que resultaram no lançamento de vários híbridos de milho resistentes (Scott \& Louie, 1996). No entanto, esses híbridos não são adaptados para produção comercial no Brasil.

Embora muitos híbridos comerciais de milho sejam altamente susceptíveis a essa doença, já foi identificada, em pesquisas desenvolvidas na Embrapa Milho e Sorgo, a existência de germoplasma tropical resistente, que poderá contribuir em muito para programas de melhoramento visando à obtenção de cultivares de milho (Souza et $a l ., 2003)$. Para o sucesso de programas de melhoramento que visem transferir genes de resistência ao mosaico comum do milho, torna-se necessário o conhecimento do controle genético da resistência.

Assim sendo, o presente trabalho teve como objetivos determinar o número de genes conferindo resistência ao mosaico comum em linhagens de milho tropical e verificar a ocorrência de alelismo entre essas linhagens resistentes.

\section{Material e Métodos}

As linhagens de milho tropical resistentes R (L18 e L520) e susceptível - S (L19) à virose do mosaico comum, pertencentes ao Programa de Melhoramento da Embrapa Milho e Sorgo, foram intercruzadas, obtendo-se os híbridos $\mathrm{F}_{1}$ e as respectivas populações $\mathrm{F}_{2}, \mathrm{RC}_{1.1}$ e $\mathrm{RC}_{1.2}$. 
As linhagens genitoras, juntamente com os indivíduos das populações $\mathrm{F}_{2}$ e dos retrocruzamentos, foram avaliadas em condições de campo, em área experimental da Embrapa Milho e Sorgo, localizada em Sete Lagoas, MG, nos meses de dezembro de 2000 e janeiro de 2001. Além desse, realizou-se experimento complementar nos meses de abril e maio, envolvendo L520, L19 e as populações F1 e F2, provenientes do intercruzamento dessas linhagens. O delineamento experimental utilizado foi inteiramente ao acaso, com diferentes números de repetições. Cada parcela consistiu de uma fileira de $4 \mathrm{~m}$, apresentando, em média, 20 plantas. As práticas culturais foram similares às empregadas em cultivos comerciais.

O inóculo utilizado no experimento foi obtido de plântulas cultivadas em canteiro e previamente infectadas com o complexo viral do mosaico comum, proveniente de diferentes plantas e campos de cultivo. $\mathrm{O}$ inóculo foi preparado pela maceração de folhas de plantas de milho com sintomas de mosaico comum em tampão fosfato $0,01 \mathrm{M}, \mathrm{pH} 7,4$ na proporção de 1:5 (peso/volume). Todas as plantas do experimento foram inoculadas através da fricção do inóculo em plântulas no estádio de duas a três folhas, após pulverização com carborundo 600 mesh e, em seguida, lavadas com água. (Almeida et al., 2000).

Tanto no estudo do controle da resistência quanto no teste de alelismo, as plantas foram avaliadas fenotipicamente, para presença ou ausência de sintomas de mosaico, aos 15 e aos 30 dias após a inoculação. A ocorrência de complementação gênica foi avaliada nas gerações $\mathrm{F}_{1}$ e $\mathrm{F}_{2}$ do cruzamento entre as linhagens resistentes L18 e L520.

Os dados obtidos foram submetidos a análises genético-estatística pelo teste de $\mathrm{c}^{2}$, utilizandose o programa Genes (Cruz, 2001).

\section{Resultados e Discussão}

No cruzamento envolvendo as linhagens de milho L18 (R) e L19 (S), 100\% das plantas $\mathrm{F}_{1}$ mostraram-se resistentes ao mosaico comum, nas avaliações realizadas aos 15 e aos 30 dias após a inoculação (Tabela 1). As frequiências fenotípicas observadas nas gerações $\mathrm{F}_{2}$ e $\mathrm{RC}_{1.2}$ não foram estatisticamente diferentes das freqüências esperadas pelo teste do $c^{2}$, aos 30 dias após a inoculação, o que permite concluir que a resistência ao mosaico comum do milho presente na linhagem L18 é governada por um gene com dominância completa. Pela comparação dos resultados das avaliações realizadas nas duas épocas, verificou-se que a fenotipagem realizada aos 30 dias após a inoculação permitiu identificar plantas susceptíveis que haviam sido classificadas como resistentes aos 15 dias. McMullen \& Louie (1989), ao estudar o controle genético da manifestação do MDMV, verificaram que, em determinadas populações segregantes, plantas classificadas como resistentes em estádios iniciais desenvolveram posteriormente sintomas da doença. A explicação para tal fato seria de que o alelo dominante $M d m 1$, que retarda o aparecimento de sintomas dessa virose, não determina a completa imunidade ao agente causal da doença, além de ser dependente do genótipo do genitor susceptível (McMullen \& Louie, 1989; Ignajatovic et al., 1995).

A linhagem L520, caracterizada como resistente ao mosaico comum, mostrou-se parcialmente susceptível nas avaliações realizadas aos 15 e 30 dias após a inoculação (Tabela 2). No entanto, pelo teste de qui-quadrado nas populações $\mathrm{F}_{2}$, utilizando-se a avaliação realizada aos 15 dias após a inoculação, foi possível inferir que a resistência à virose do mosaico comum é conferida por um gene dominante. Para confirmar a hipótese (Tabela 3), realizou-se um experimento complementar nos meses de abril e maio de 2001, onde foi verificado que L520 e a geração $F_{1}$ mostravam-se completamente resistentes e que a geração $\mathrm{F}_{2}$ apresentava uma proporção fenotípica de 3(R):1(S), típica de um gene com dominância completa. 
TABELA 1. Frequiências observadas e esperadas para resistência e susceptibilidade ao mosaico comum do milho, valores dos quiquadrados e das probabilidades de erro ao rejeitar a razão de segregação nas linhagens resistente (L18) e susceptível (L19), no híbrido $\mathrm{F}_{1}$, na geração $\mathrm{F}_{2}$ e nos retrocruzamentos (RCs).

\begin{tabular}{|c|c|c|c|c|c|c|c|c|c|c|c|}
\hline \multirow[b]{3}{*}{ Geraçầo } & \multirow{3}{*}{$\begin{array}{l}\text { Genótipo ou } \\
\text { cruzamento }\end{array}$} & \multicolumn{10}{|c|}{ Número de plantas avaliadas } \\
\hline & & \multicolumn{5}{|c|}{15 dias após inoculaçã̃o } & \multicolumn{5}{|c|}{$\mathbf{3 0}$ dias após inoculação } \\
\hline & & $\begin{array}{c}\text { Resistente } \\
\text { (R) }\end{array}$ & $\begin{array}{c}\text { Susceptivel } \\
\text { (S) }\end{array}$ & $\begin{array}{c}\text { Proporcĩo } \\
\text { Esperada } \\
\text { (R:S)* }\end{array}$ & $\chi^{2}$ & Prob. & $\begin{array}{c}\text { Resistente } \\
\text { (R) }\end{array}$ & $\begin{array}{c}\text { Susceptivel } \\
\text { (S) }\end{array}$ & $\begin{array}{c}\text { Proporção } \\
\text { Esperada } \\
\text { (R:S) }\end{array}$ & $x^{2}$ & Prob. \\
\hline$P_{1}$ & L18 & 24 & 0 & $1: 0$ & - & - & 24 & 0 & $1: 0$ & - & - \\
\hline $\mathrm{P}_{2}$ & L19 & 0 & 18 & $0: 1$ & - & - & 0 & 18 & $0: 1$ & - & - \\
\hline $\mathrm{F}_{\mathrm{i}}$ & (L18 x L19) & 21 & 0 & $1: 0$ & - & $\cdot$ & 20 & 1 & $1: 0$ & - & - \\
\hline $\mathrm{F}_{2}$ & $F_{1}$ autofocundado & 190 & 41 & $3: 1$ & 6,47 & 0,01 & 180 & 50 & $3: 1$ & 1,3 & 0.25 \\
\hline $\mathrm{RC}_{1.1}$ & $F_{1}(L 18 \times L 19) \times L 18$ & 109 & 1 & $1: 0$ & 0,009 & 0,92 & 108 & 2 & $1: 0$ & 0,036 & 0.85 \\
\hline $\mathrm{RC}_{1.2}$ & $\mathrm{~F}_{1}(\mathrm{~L} 18 \times \mathrm{L} 19) \times \mathrm{L} 19$ & 80 & 45 & $1: 1$ & 9,8 & 0,002 & 73 & 52 & $1: 1$ & 3,53 & 0,06 \\
\hline
\end{tabular}

* R:S - proporção de plantas resistentes para susceptíveis.

TABELA 2. Freqüências observadas e esperadas para resistência e susceptibilidade ao mosaico comum do milho, valores dos quiquadrados e das probabilidades de erro ao rejeitar a razão de segregação nas linhagens resistente (L520) e susceptível (L19), no híbrido $F_{1}$, na geração $\mathrm{F}_{2}$ e nos retrocruzamentos (RCs).

\begin{tabular}{|c|c|c|c|c|c|c|c|c|c|c|c|}
\hline \multirow{3}{*}{ Geraçño } & \multirow{3}{*}{$\begin{array}{l}\text { Genótipo ou } \\
\text { cruzamento }\end{array}$} & \multicolumn{10}{|c|}{ Número de plantas avaliadas } \\
\hline & & \multicolumn{5}{|c|}{15 dias após inoculação } & \multicolumn{5}{|c|}{30 dias após inoculaçâo } \\
\hline & & $\begin{array}{c}\text { Resistente } \\
\text { (R) }\end{array}$ & $\begin{array}{l}\text { Susceptivel } \\
\text { (S) }\end{array}$ & $\begin{array}{c}\text { Proporção } \\
\text { Esperada } \\
\text { (R:S)^ }\end{array}$ & $x^{2}$ & Prob. & $\begin{array}{c}\text { Resistente } \\
\text { (R) }\end{array}$ & $\begin{array}{c}\text { Susceptivel } \\
\text { (S) }\end{array}$ & $\begin{array}{c}\text { Proporção } \\
\text { Esperada } \\
(\mathrm{R}: S)^{*}\end{array}$ & $x^{2}$ & Prob. \\
\hline $\mathbf{P}_{1}$ & L520 & 5 & 18 & $1: 0$ & - & - & 1 & 20 & $1: 0$ & - & - \\
\hline $\mathbf{P}_{2}$ & L19 & 13 & 11 & $0: 1$ & $=$ & $=$ & 3 & 21 & $0: 1$ & $=$ & $=$ \\
\hline $\mathbf{F}_{1}$ & (L520 x L19) & 13 & 11 & 1:0 & - & - & 6 & 12 & 1:0 & - & - \\
\hline $\mathbf{F}_{2}$ & $F_{1}$ autofecundado & 165 & 59 & $3: 1$ & 0,21 & 0,64 & 150 & 72 & $3: 1$ & 9,14 & 0,002 \\
\hline $\mathrm{RC}_{\sqcup \mathrm{U}}$ & $F_{1}(L 520 \times L 19) \times L 520$ & 58 & 44 & 1:0 & 18,98 & 0,002 & 42 & 55 & 1:0 & 31,18 & 0,003 \\
\hline $\mathbf{R C}_{12}$ & $\mathrm{~F}_{1}(\mathrm{~L} 520 \times \mathrm{L} 19) \times \mathrm{L} 19$ & 63 & 51 & $1: 1$ & 1,26 & 0,26 & 40 & 72 & 1:1 & 6,54 & 0,01 \\
\hline
\end{tabular}

* R:S - proporção de plantas resistentes para susceptíveis. 


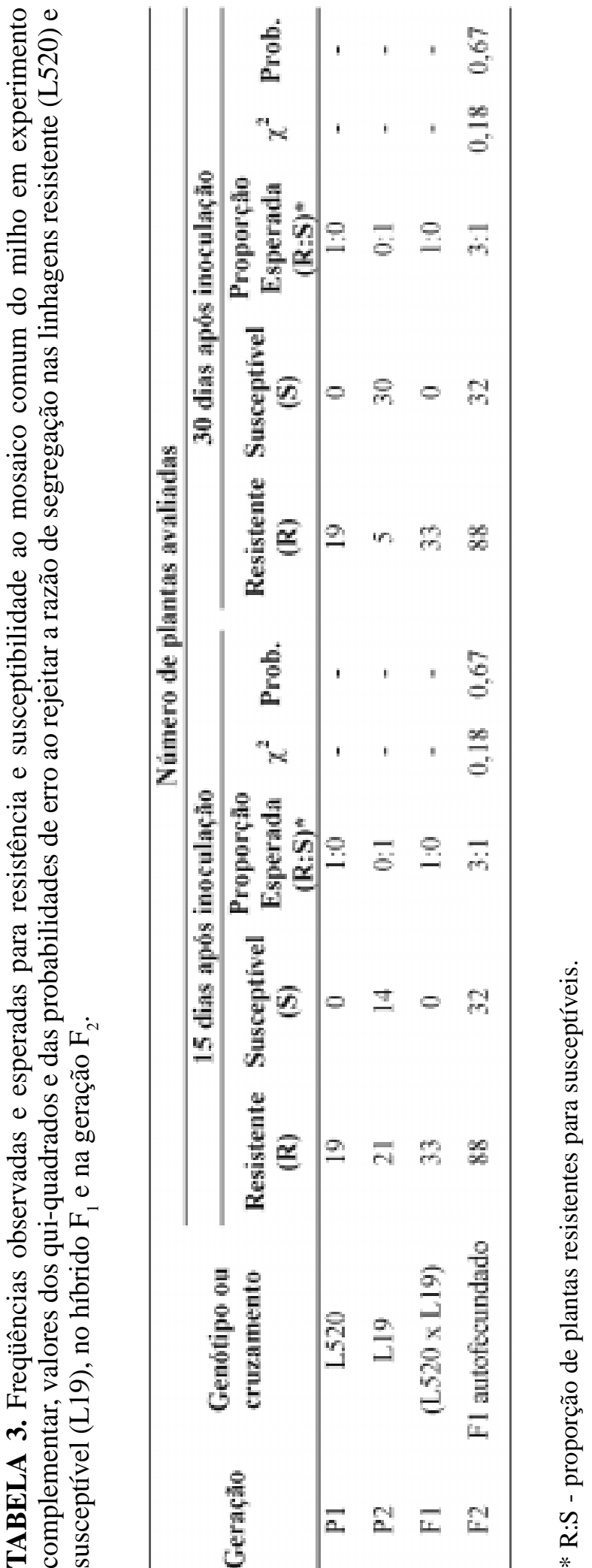

Melchinger et al. (1998), ao estudar a base genética da resistência de germoplasma de milho ao SCMV, verificaram, em experimentos realizados em diferentes locais, que variações nas temperaturas médias produziam alterações significativas na proporção de plantas susceptíveis em gerações segregantes e não segregantes. Dentre os fatores ambientais que podem interferir no nível de resistência, temperaturas elevadas promovem o incremento do número de plantas com sintomas da doença (Tu $\&$ Ford, 1969). Essa observação reforça os resultados obtidos no presente trabalho, visto que a média das temperaturas mínimas $\left(19,07^{\circ} \mathrm{C}\right)$ e máximas $\left(30,1^{\circ} \mathrm{C}\right)$ registradas na Embrapa Milho e Sorgo de dezembro de 2000 a janeiro de 2001, período em que foram coletados os dados, foram superiores em relação às mínimas $\left(17,05^{\circ} \mathrm{C}\right)$ e máximas $\left(30^{\circ}\right.$ C) registradas nos meses de abril e maio de 2001. Assim, a linhagem L520, caracterizada como resistente, pode ter apresentado sintomas do mosaico comum em função de temperaturas mínimas mais elevadas. No entanto, as modificações nas proporções fenotípicas podem ser devida também ao tipo de inóculo. Nesse contexto, a inoculação foi realizada com inóculo proveniente de plantas infectadas no campo, que pode apresentar variabilidade genética quanto à virulência. Conseqüentemente, o aparecimento de sintomas dependeria das constituições genéticas para resistência e virulência, do hospedeiro e do vírus, respectivamente.

No teste de alelismo (Tabela 4), constatouse que a linhagem $L 18$ e o híbrido $F_{1}$ apresentaram $100 \%$ de plantas resistentes, enquanto a linhagem L520 apresentou plantas susceptíveis e resistentes. Esses resultados levam a hipotetizar que a linhagem L520 contenha algum fator genético, altamente influenciado pelas condições ambientais, que interfere na expressão da resistência e que, no híbrido $\mathrm{F}_{1}$, há supressão desse efeito pela contribuição do genótipo da L18 na progênie, menos sensível aos efeitos ambientais. 


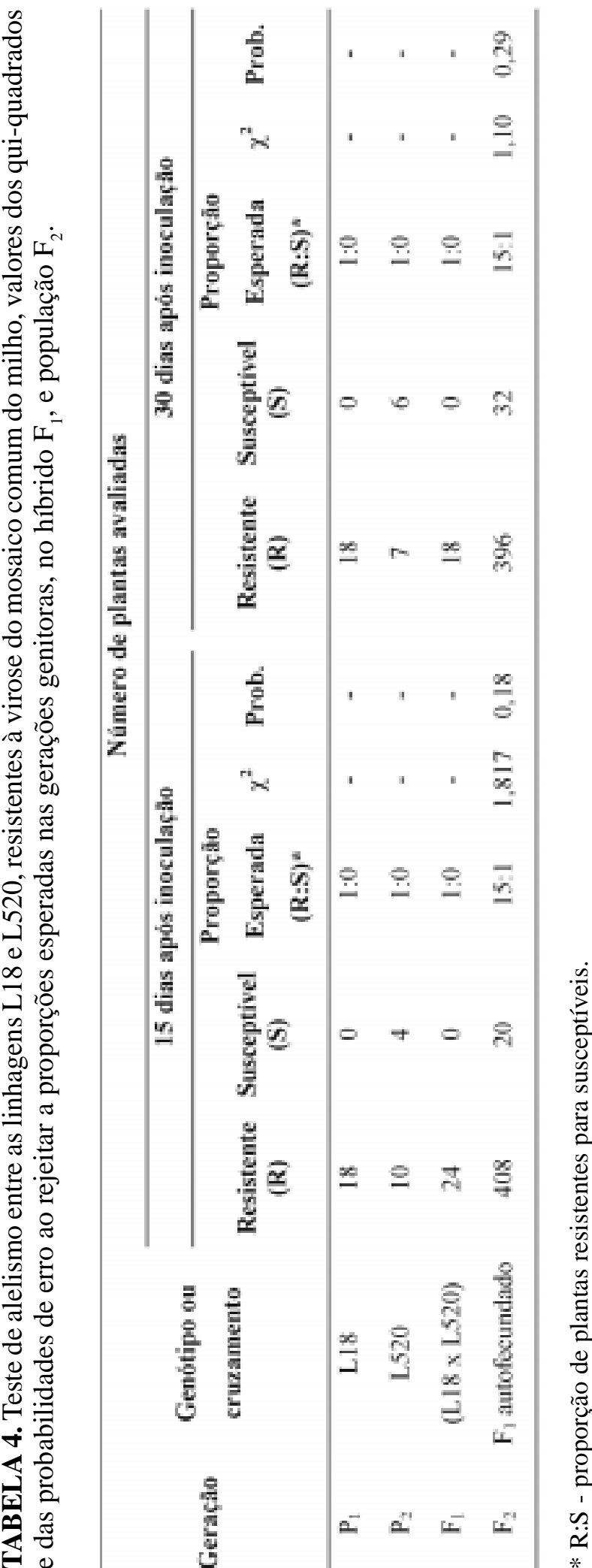

Os testes de qui-quadrado aplicados aos dados obtidos avaliando-se os indivíduos da população $F_{2}$ aos 15 e 30 dias após a inoculação (Tabela 4), permitem inferir que dois genes dominantes segregando independentemente governam a expressão da resistência. No entanto, a presença de apenas um desses genes é suficiente para expressar a resistência. Assim, pelo teste de alelismo, verificase que o gene que confere resistência na L18 é diferente daquele na L520. Entretanto, esses resultados devem ser interpretados com cautela, devido à possível instabilidade genética da resistência conferida pela L520.

Embora vários estudos tenham sido realizados com o intuito de estabelecer o controle genético da resistência ao mosaico comum (Roane et al., 1977; Findley et al., 1984; Mikel et al., 1984; Rosenkranz \& Scott, 1984; McMullen \& Louie, 1989; Louie et al., 1991; Melchinger et al., 1998), os resultados têm sido bastante discrepantes, uma vez que diferentes fontes de resistência, linhagens susceptíveis, estirpes e/ou espécies de potyvirus e parâmetros de avaliação têm sido empregados, dificultando a comparação de resultados (Melchinger et al., 1998). Nesse contexto, o emprego de marcadores moleculares de DNA e a avaliação fenotípica em diferentes condições de ambiente possibilitarão a elucidação de regiões genômicas associadas à resistência na L18 e L520, bem como o seu monitoramento no processo de transferência para linhagens-elites. Nesse sentido, estão sendo desenvolvidas atividades de mapeamento de possíveis regiões genômicas que conferem a resistência ao vírus do mosaico comum nas linhagens de milho tropical L18 e L520, visto que as informações disponíveis têm sido geradas com germoplasma temperado.

\section{Conclusões}

O controle da resistência genética das linhagens L18 e L520 à virose do mosaico comum do 
milho é conferido por um gene com dominância completa.

As linhagens L18 e L520 apresentam genes distintos para resistência.

A resistência conferida pela linhagem L18 é estável em relação às variações de temperatura.

A avaliações em experimentos com inoculação de potyvirus em milho devem ser realizadas aos 15 e 30 dias, para permitir a expressão de sintomas em plantas susceptíveis.

\section{Agradecimentos}

Os autores agradecem ao Pronex/Finep e ao Prodetab (processo 162-01/98) o suporte financeiro parcial e à Fapemig a concessão de uma bolsa (processo GAG 0001/00), modalidade recém-doutor, ao primeiro autor.

\section{Literatura Citada}

ALMEIDA, A. C. L.; OLIVEIRA E.; RESENDE, R. Detecção de vírus por RT-PCR, hibridação "dotblot" e dot-ELISA em milho com mosaico comum. Fitopatologia Brasileira, Brasília, v. 25, p. 168 170, 2000.

ALMEIDA, A. C. L.; OLIVEIRA E.; RESENDE, R. Fatores relacionados à incidência e disseminação do vírus do mosaico comum do milho. Fitopatologia Brasileira, Brasília, v. 26, n. 4, p. $766-769,2001$.

CRUZ, C. D. Programa Genes: aplicativo computacional em genética e estatística. Viçosa: UFV, 2001. $648 \mathrm{p}$.

FINDLEY, W. R.; LOUIE, R.; KNOKE, J. K. Breeding corn for resistance to corn viruses in Ohio. In: ANNUAL CORN AND SORGHUM RESOURCES CONFERENCE, 39., Chicago. Procedings... Washington: ASTA, 1984.p. 52 - 67.

IGNJATOVIC, I.; IVANOVIC, D; TADIC, B. Associations of isozyme marker-genes on chromosome 6 with resistance to MDMV in maize. Agronomie, Paris, v. 15, p.487 - 490, 1995.

LOUIE, R.; FINDLEY, W. R.; KNOKE, J. K.; McMULLEN, M. D. Genetic basis of resistance in maize to five maize dwarf mosaic virus strains. Crop Science, Madison, v. 31, p.14 - 18, 1991.

MELCHINGER, A. E.; KUNTZE, L.; GUMBER, R. K.; LÜBBERSTEDT, T.; FUCHS, E. Genetic basis of resistance to sugarcane mosaic virus in European maize germplasm. Theoretical and Applied Genetics, Berlin, v. 96, p.1151 - 1161, 1998.

MELLO, P. R. Estudo da variabilidade e do uso de métodos moleculares na detecção dos vírus do rayado fino e do mosaico comum do milho (Zea mays L.). 2000.104f. Tese (Mestrado) Universidade de Brasília, Brasília.

McMULLEN, M. D.; LOUIE, R. The linkage of molecular markers to a gene controlling the symptom response in maize to maize dwarf mosaic virus. Molecular Plant-Microbe Interactions, Saint Paul, v.2, p. 309 - 314, 1989.

MIKEL, M. A.; D’ARCY, C. J.; RHODES, A. M.; FORD, R. E. Genetics of resistance of two corn inbreds to maize dwarf mosaic virus and transfer of resistance into sweet corn. Phytopathology, Saint Paul, v.74, p. 467 - 473, 1984.

ROANE, C. W.; GENTER, C. F.; TOLIN, S. A. Inheritance of resistance to maize dwarf mosaic virus in maize. Proceedings of the American Phytopathology Society, v. 4, p.140, 1977. Suplement.

ROSENKRANZ, E.; SCOTT, G. E. Determination of the number of genes for resistance to maize dwarf mosaic virus strain A in five corn inbred lines. Phytopathology, Saint Paul, v. 74, p.71 - 76, 1984. 
SOUZA, I. R. P.; OLIVEIRA, E.; PERES, M. A.; OliveirA, A. C.; PURCINO, A. A. C. Peroxidase activity in maize inbred lines resistant or susceptible to maize dwarf mosaic virus. Revista Brasileira de Milho e Sorgo, Sete Lagoas, v. 2, n. 1, p. 1 - 8, 2003.

SCOTT, G. E.; LOUIE, R. Improved resistance to maize dwarf mosaic virus by selection under greenhouse conditions. Crop Science, Madison, v. 36, p.1503 - 1506, 1996.

SHUKLA, D. D.; WARD, C. W.; BRUNT, A. A. Case histories of some important potyviruses. In: SHUKLA SHUKLA, D. D.; WARD, C. W.; BRUNT, A. A., The Potyuvyridae. Cambridge: University Press, 1994. cap. 11, p. 322 - 329.
TU, J. C.; FORD, R. E. Effect of temperature on maize dwarf mosaic virus infection, incubation, and multiplication in corn. Phytopathology, Saint Paul, v. 59, p. 699 - 702, 1969.

WAQUIL, J. M.; OLIVEIRA, E.; PINTO, N. F. J. A.; FERNANDES, F. F.; CORRÊA, L. A. Efeito na produção e incidência de viroses em híbridos comerciais de milho. Fitopatologia Brasileira, Brasília, v. 21, n. 4, p.460 - 463, 1996.

WILLIAMS, L. E.; ALEXANDER, L. J. Maize dwarf mosaic, a new corn disease. Phytopathology, Saint Paul, v. 55, p. 802 - 804, 1965. 